\begin{tabular}{|c|l|}
\hline Title & A pparent Coal Viscosity Estimated from Needle Penetration into Pellet of Pulverized Coal Particles \\
\hline Author(s) & Matsuoka, Koichi; Kumagai, Takehiko; Chiba, Tadatoshi \\
\hline Citation & $\begin{array}{l}\text { ISIJ International, 36(1), 40-44 } \\
\text { https://doi.org/40.2355/Sijinternational.36.40 }\end{array}$ \\
\hline Issue Date & 1996-01-15 \\
\hline Doc URL & http://hdl.handle.net/2115/75027 \\
\hline Rights & article \\
\hline Type & isij 36(1) 40.pdf \\
\hline File Information & \\
\hline
\end{tabular}

Instructions for use 


\title{
Apparent Coal Viscosity Estimated from Needle Penetration into Pellet of Pulverized Coal Particles
}

\author{
Koichi MATSUOKA, Takehiko KUMAGAI ${ }^{1)}$ and Tadatoshi CHIBA \\ Center for Advanced Research of Energy Technology, Hokkaido University, N13 W8, Kita-ku, Sapporo, Hokkaido, 060 Japan. \\ 1) Graduate School of Engineering, Hokkaido University, N13 W8, Kita-ku, Sapporo, Hokkaido, 060 Japan.
}

(Received on June 15, 1995; accepted in final form on July 24, 1995)

\begin{abstract}
Needle penetration and volumetric dilation were measured for cylindrical pellets of six kinds of pulverized coal particles using a needle penetrometer. The measurements were conducted for a range of the heating rate from 1 to $20 \mathrm{~K} / \mathrm{min}$, the holding temperature from 698 to $823 \mathrm{~K}$ and the nitrogen gas pressure from 0.1 to $3.0 \mathrm{MPa}$. Both needle penetration and dilation characteristics depended on these operating variables. Especially, an appreciable needle penetration occurred at high heating rate for coals which exhibited little softening property at low heating rate. Unreasonably high activation energies for viscosity were obtained when the needle penetration curves were analyzed on the basis of an equation of motion assuming that the pellet behaves as a Newtonian fluid with a temperature dependency of viscosity given by Andrade's equation.
\end{abstract}

KEY WORDS: coal; needle penetration; dilation; heating rate; viscosity; thermal plasticity; Andrade's equation.

\section{Introduction}

Thermal plasticity is one of the fundamental properties that coal exhibits when heated above $c a .550$ to $600 \mathrm{~K}$. Deng et al. ${ }^{1)}$ developed a novel needle penetrometer to evaluate softening and solidification properties of pelletized Drummond coal in terms of needle penetration and relative degree of volumetric dilation. Examining effects of the heating rate, the gas pressure and the gas atmosphere, they showed that the needle penetration and the dilation depend on these operating variables. Furthermore, analysis of the observed needle penetration curves in a limited temperature range was carried out to estimate the coal viscosity based on an equation of motion which assumes that the coal behaves as a Newtonian fluid with an apparent viscosity change with temperature given by Andrade's equation. The apparent activation energies for viscosity thus obtained varied from 418 to $1339 \mathrm{~kJ} / \mathrm{mol}$ depending on the above operating variables.

As is well known, thermal plasticity of coal depends not only on the operating variables above mentioned but also on original coal nature. ${ }^{2-7)}$ Hence, in this paper the needle penetration and the coal dilation characteristics are described which were observed for six different kinds of coals ranging from 'caking' to 'noncaking' coals in a wider range of the heating rate, the holding temperature and the gas pressure. The observed needle penetration curves are also analyzed by the equation of motion in a full experimental range of temperature and effect of coal nature on the apparent viscosity is extensively discussed.

\section{Experimental}

\subsection{Coal Sample}

Six kinds of coals were so far used as sample. They had different elemental compositions, ash and volatile matter contents as listed in Table 1. Since little difference was found in the the needle penetration and the dilation characteristics for a cylindrical block quarried from coal lump and a pellet of pulverized coal, ${ }^{1)}$ the latter was used here by pulverizing each coal sample into powders with a size range less than 100 mesh. $0.5 \mathrm{~g}$ of the powders were pelletized in the same method as that by Deng et al., ${ }^{1)}$ applying $785 \mathrm{MPa}$ mechanical pressure. The pellets were $10.0 \mathrm{~mm}$ in diameter but different in height, $H_{0}$, and in density, $\rho_{0}$, for different kinds of coals.

\subsection{Apparatus}

The present experimental apparatus and procedure were much the same as employed by Deng et al. ${ }^{13}$ Figure 1 shows a schematic diagram of the apparatus. The coal pellet was settled in a $10.6 \mathrm{~mm}$ i.d. steel cell which was fixed in a $50 \mathrm{~cm}^{3}$ micro-autoclave. For measurement of needle penetration a $2.0 \mathrm{~mm}$ o.d. cylindrical rod was used as a needle with a mass of $17 \mathrm{~g}$ and was placed on the center of the upper surface of the pellet while a $10.0 \mathrm{~mm}$ o.d. and $2.4 \mathrm{~mm}$ thick stainless steel disc was attached to the bottom tip of the rod for measurement of volumetric dilation of the pellet. The vertical movement of the rod was detected by a linear-variable differential transformer.

The autoclave was heated in an infrared image furnace at a heating rate of 1 to $20 \mathrm{~K} / \mathrm{min}$ from $298 \mathrm{~K}$ to a holding temperature between 698 and $823 \mathrm{~K}$ under $\mathrm{N}_{2}$ gas 
Table 1. Relevant properties of coal samples so far used.

\begin{tabular}{|c|c|c|c|c|c|c|c|c|c|c|c|c|c|c|}
\hline \multirow{2}{*}{ Coal } & \multirow{2}{*}{ (Abbr.) } & \multicolumn{5}{|c|}{ Elemental composition } & \multicolumn{2}{|c|}{ Proximate analysis } & \multicolumn{4}{|c|}{ Gieseler's fluidity parameters } & \multicolumn{2}{|c|}{ Pellet } \\
\hline & & $\mathrm{C}$ & $\begin{array}{l}\mathrm{H} \\
(\mathrm{d}\end{array}$ & $\begin{array}{l}\mathrm{O}^{\mathrm{a}} \\
\mathrm{f}^{\mathrm{b}}{ }^{\mathrm{b}} \mathrm{wt}\end{array}$ & S & $\mathrm{N}$ & $\begin{array}{l}\text { Ash } \\
\text { (m.f. }\end{array}$ & $\begin{array}{l}\text { Volatile } \\
\mathrm{wt} \%)\end{array}$ & $\begin{array}{l}\mathrm{ST}^{\mathrm{d}} \\
(\mathrm{K})\end{array}$ & $\begin{array}{l}\mathrm{MFT}^{\mathrm{c}} \\
(\mathrm{K})\end{array}$ & $\begin{array}{l}\mathrm{FT}^{\mathrm{f}} \\
(\mathrm{K})\end{array}$ & $\begin{array}{c}\log (\mathrm{MF} / \mathrm{ddpm}) \\
(-)\end{array}$ & $\begin{array}{c}\mathrm{H}_{0} \\
(\mathrm{~mm})\end{array}$ & $\begin{array}{c}\rho_{0} \\
\left(\mathrm{~g} / \mathrm{cm}^{3}\right.\end{array}$ \\
\hline Akabira & (AKA) & 80.7 & 5.9 & 10.5 & 0.6 & 2.3 & 4.2 & 40.6 & 620 & 705 & 733 & 2.5 & 5.6 & 1.14 \\
\hline Cerrejon & (CER) & 82.3 & 5.5 & 10.1 & 0.5 & 1.6 & 1.0 & 37.7 & & imposs & ible $t$ & measure & 6.1 & 1.19 \\
\hline Black Water & (BLW) & 86.8 & 4.9 & 5.8 & 0.4 & 2.1 & 7.7 & 26.4 & 687 & 725 & 752 & 2.51 & 5.4 & 1.20 \\
\hline Goonyella & (GOO) & 87.4 & 4.9 & 5.2 & 0.6 & 2.0 & 7.6 & 26.4 & 681 & 735 & 769 & 3.25 & 5.2 & 1.05 \\
\hline Byron Creek & (BYC) & 86.0 & 4.7 & 7.5 & 0.3 & 1.5 & 11.2 & 23.8 & 700 & 725 & 746 & 0.48 & 5.3 & 1.23 \\
\hline $\begin{array}{c}\text { Peak Downs } \\
\text { Highway }\end{array}$ & $(\mathrm{PDH})$ & 88.4 & 4.9 & 3.9 & 0.6 & 2.1 & 10.0 & 21.4 & 695 & 743 & 775 & 2.56 & 4.9 & 1.30 \\
\hline
\end{tabular}

a; by difference, b; dry-ash-free, $c$; moisture-free, $d$; softening point temperature, e; maximum fluidity temperature f; solidification point temperature.

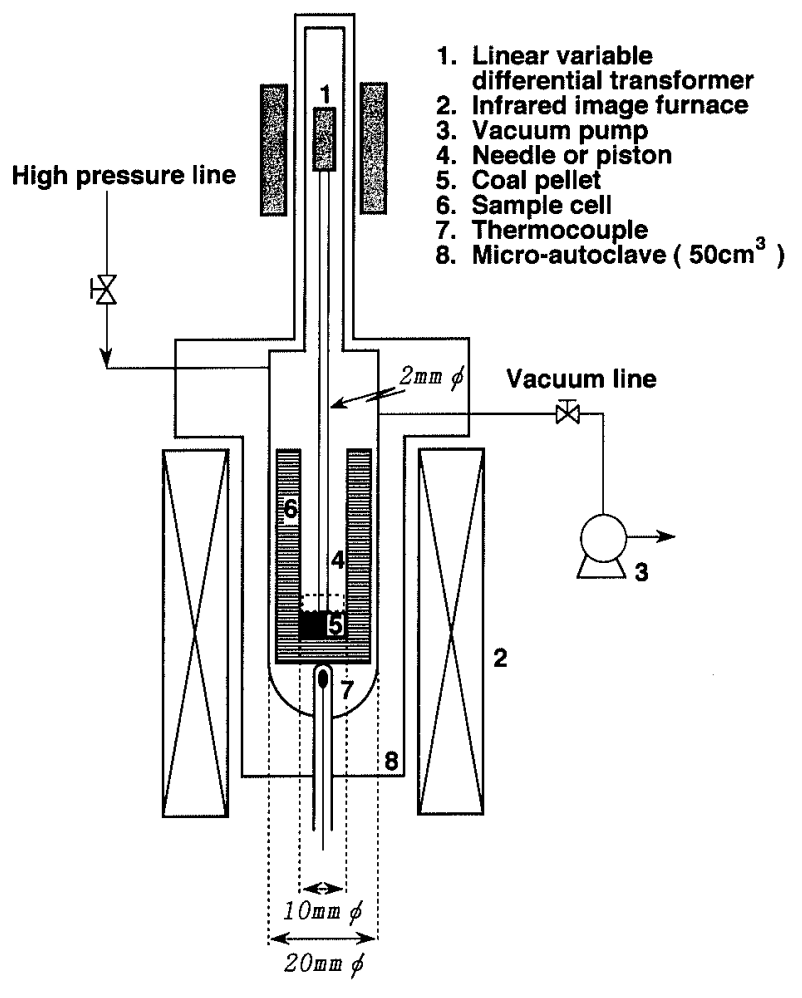

Fig. 1. Schematic diagram of experimental apparatus.

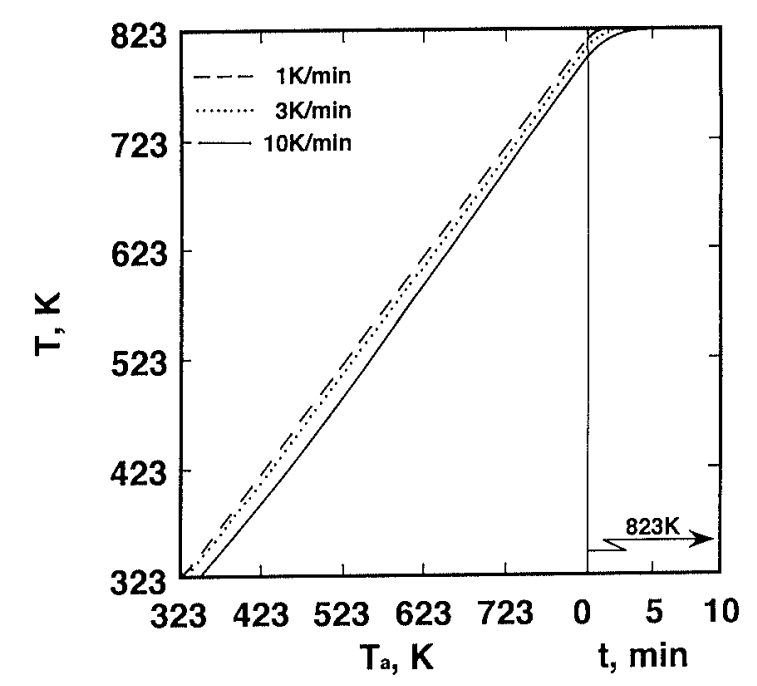

Fig. 2. Difference between temperature at pellet center, $T$, and that at autoclave bottom, $T_{\mathrm{a}}$, at various heating rates.
Table 2. Correlation between temperature at pellet center, $T$, and that at autoclave bottom, $T_{\mathrm{a}}$, at various heating rates.

\begin{tabular}{cc}
\hline$q_{\mathrm{h}}(\mathrm{K} / \mathrm{min})$ & Correlations \\
\hline 1 & $T=0.989 \times T_{\mathrm{a}}+2.567$ \\
2 & $T=0.993 \times T_{\mathrm{a}}-2.350$ \\
3 & $T=1.006 \times T_{\mathrm{a}}-16.054$ \\
10 & $T=1.039 \times T_{\mathrm{a}}-53.249$ \\
\hline
\end{tabular}

pressures from 0.1 to $3.0 \mathrm{MPa}$. The needle penetration and the pellet dilation measurements were conducted separately for a pair of pellets of the same coal. A preliminary experiment was carried out to correlate the observed temperature, $T_{\mathrm{a}}$, at the bottom of the autoclave to the temperature, $T$, at the center of the pellet. In Fig. 2 is shown an example of the observed difference between $T$ and $T_{\mathrm{a}}$ for AKA coal at different heating rates and $0.1 \mathrm{MPa}-\mathrm{N}_{2}$. The difference amounts 2 to $20 \mathrm{~K}$ and is seen to increase with the heating rate. At each heating rate a linear correlation between $T$ and $T_{\mathrm{a}}$ was assumed as summarized in Table 2 which was obtained by a least-square method for $500 \mathrm{~K}<T_{\mathrm{a}}<800 \mathrm{~K}$. The temperatures referred hereafter indicate $T$ calculated from observed $T_{\mathrm{a}}$ on the basis of the correlations.

\section{Results and Discussion}

\subsection{Results of Needle Penetration and Dilation}

Figure 3 shows changes with temperature of the apparent needle penetration depth, $H$, the relative degree of volumetric dilation, $Q$, and the net needle penetration depth, $h$, when a pellet of AKA coal was heated at different heating rates, $q_{\mathrm{h}}$, up to a holding temperature, $T_{\mathrm{s}}$, of $773 \mathrm{~K}$ under $1.0 \mathrm{MPa}$. Here, $H, Q$ and $h$ are defined as

$$
\begin{gathered}
H=H_{0}-H_{\mathrm{t}} \\
Q=H_{\mathrm{p}} / H_{0} \\
h=\left(Q H_{0}-H_{\mathrm{t}}\right) / Q
\end{gathered}
$$

where $H_{0}, H_{\mathrm{t}}$ and $H_{\mathrm{p}}$ represent the initial pellet height, the distance from the bottom tip of the needle to the pellet bottom and the heated pellet height, respectively. It is seen from the figure that both needle penetration 
and dilation occur at the same temperature range from about 650 to $725 \mathrm{~K}$. These changes shift to a higher temperature range for higher $q_{\mathrm{h}}$. For $q_{\mathrm{h}}=2,3$ and $10 \mathrm{~K} / \mathrm{min}, H$ and $h$ are seen to fall off at about $5 \mathrm{~mm}$ suggesting termination of the needle penetration near the pellet bottom while at the slowest heating rate of $1 \mathrm{~K} / \mathrm{min}$

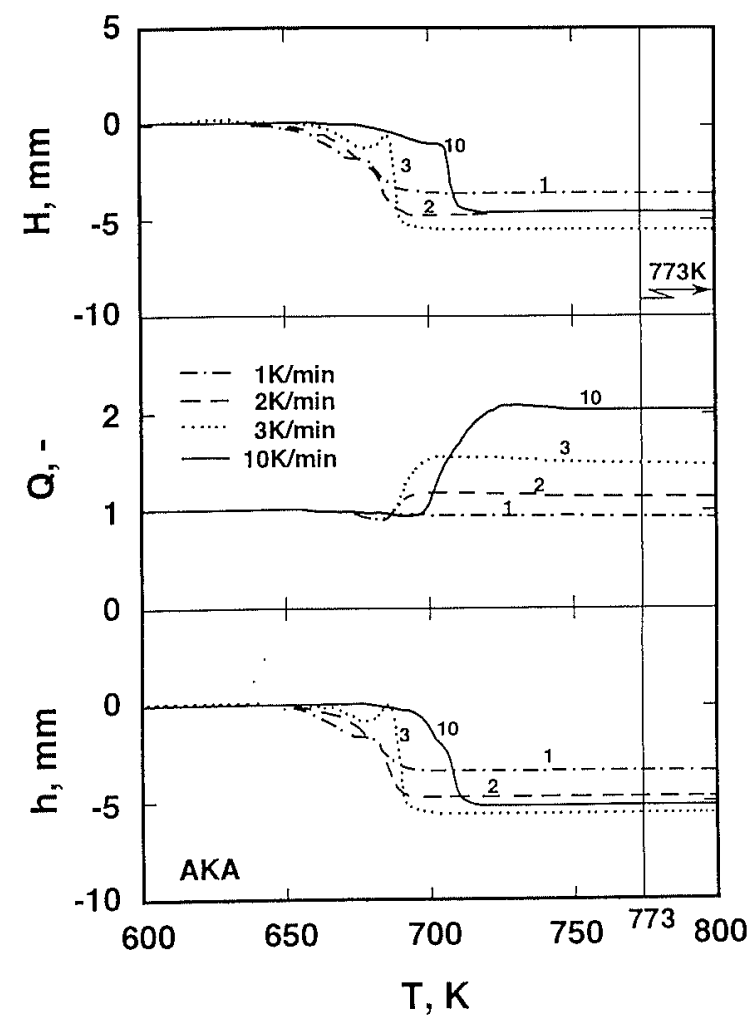

Fig. 3. Changes with temperature of apparent needle penetration depth, $H$, relative degree of volumetric dilation, $Q$, and net needle penetration depth, $h$, at different heating rates up to $773 \mathrm{~K}$ for AKA coal under $1.0 \mathrm{MPa}$.
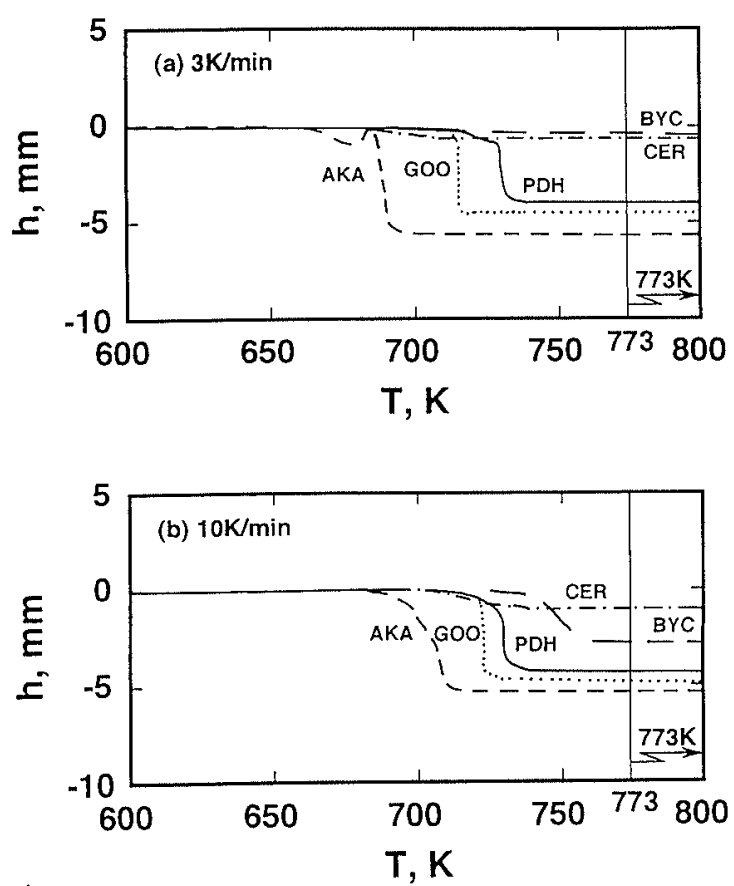

Fig. 4. Changes with temperature of net needle penetration depth at $3 \mathrm{~K} / \mathrm{min}$ (a) and $10 \mathrm{~K} / \mathrm{min}$ (b) up to $773 \mathrm{~K}$ for different coals under 1.0 MPa. the penetration terminates at $h=c a .3 \mathrm{~mm}$ before the needle reaches the bottom.

The above results were more or less similar for other kinds of coals. In Fig. 4 changes of the net needle penetration depth with temperature, i.e., $h$ vs. $T$ plots, are compared for five different kinds of coals heated at $q_{\mathrm{h}}=3 \mathrm{~K} / \mathrm{min}$ (a) and $10 \mathrm{~K} / \mathrm{min}$ (b) up to $773 \mathrm{~K}$ under 1.0 $\mathrm{MPa}$. From the figure the temperature range for occurrence of the needle penetration is seen to depend on the coals as has been indicated that the thermal plasticity in general depends on coal rank. ${ }^{8)}$ However, no regular relationship is found between the penetration curves and the carbon content or other properties of parent coals listed in Table 1 in their order of the volatile matter content from the proximate analysis. At $q_{\mathrm{h}}=3 \mathrm{~K} / \mathrm{min}$ earlier penetration occurs in the order of $\mathrm{AKA}, \mathrm{GOO}$ and PDH coals whereas little penetration is observed for BYC and CER coals. The above order for the three kinds of coals is invariable even at the higher heating rate, i.e., $10 \mathrm{~K} / \mathrm{min}$, although penetration commences at a temperature higher than at $3 \mathrm{~K} / \mathrm{min}$. On the other hand, it should be noted that an appreciable needle penetration does occur at $10 \mathrm{~K} / \mathrm{min}$ for $\mathrm{BYC}$ and CER coals, both of which exhibit little penetration propensity at $3 \mathrm{~K} / \mathrm{min}$.

The penetration curves observed at different holding temperatures, $T_{\mathrm{s}}$, are shown in Fig. 5 for AKA, BLW and $\mathrm{GOO}$ coals heated at $10 \mathrm{~K} / \mathrm{min}$ under $1.0 \mathrm{MPa}$. Here, the net needle penetration depth is plotted against the holding time, $t$, which is defined as time having elapsed after the temperature reached $T_{\mathrm{s}}$. Though not shown in the figure, the penetration was undetectable for $T_{\mathrm{s}}$ below $600 \mathrm{~K}$. For all coals, the temperature at which the

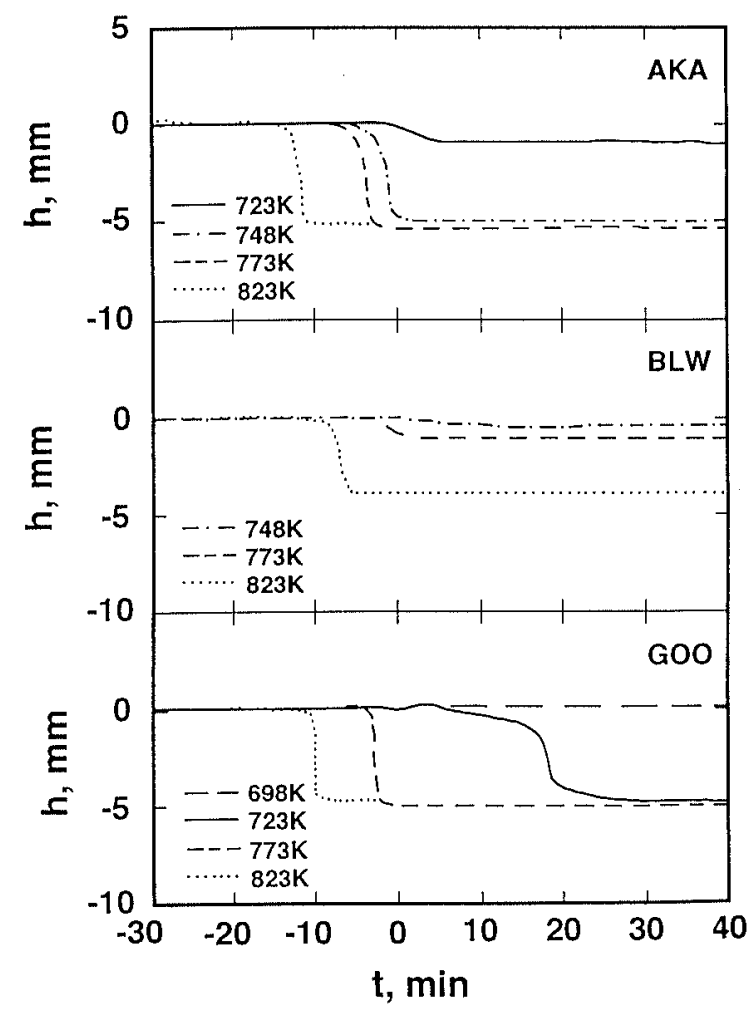

Fig. 5. Changes with holding time of net needle penetration depth at $10 \mathrm{~K} / \mathrm{min}$ up to different holding temperatures for AKA, BLW and GOO coals under $1.0 \mathrm{MPa}$. 
penetration commences is essentially independent of $T_{\mathrm{s}}$ when the penetration proceeds in a range of temperature lower than $T_{\mathrm{s}}(t<0)$. Furthermore, for cases where the penetration is observed in a range of temperature held at $T_{\mathrm{s}}(t>0)$, the rate of the needle penetration seems to be greater for higher $T_{\mathrm{s}}$.

Figure 6 demonstrates effect of the gas pressure on penetration curves for CER, BLW and $\mathrm{PDH}$ coals at $20 \mathrm{~K} / \mathrm{min}$ up to $823 \mathrm{~K}$. For PDH coal which has the lowest volatile matter content among the coals no appreciable effect can be seen, while for the other two coals having volatile matter contents higher than $\mathrm{PDH}$ coal the needle penetration is promoted as $P_{\mathrm{N} 2}$ increases. These results imply that a higher portion of light pyrolysis products is confined within the pellet at higher $P_{\mathrm{N} 2}$, resulting in a high softening property of the pellet.

\subsection{Estimation of Coal Viscosity}

In an effort to estimate the apparent viscosity of softening coal, an equation of motion was applied to analyze the observed needle penetration curves. Though softening coals could generally be treated as a nonNewtonian fluid, it is assumed here for simplicity of analysis that the coal pellet behaves as a Newtonian fluid without any chemical change along with heating ${ }^{9)}$ :

$$
h(d h / d t)=\{m g /(2 \pi \eta)\} \ln (a / b)
$$

where $m, \eta, a$ and $b$ respectively denote the mass of the needle, the apparent viscosity, the pellet and the needle diameters. Thus, the apparent viscosity is only the function of temperature for each coal and Andrade's viscosity equation, ${ }^{10}$ )

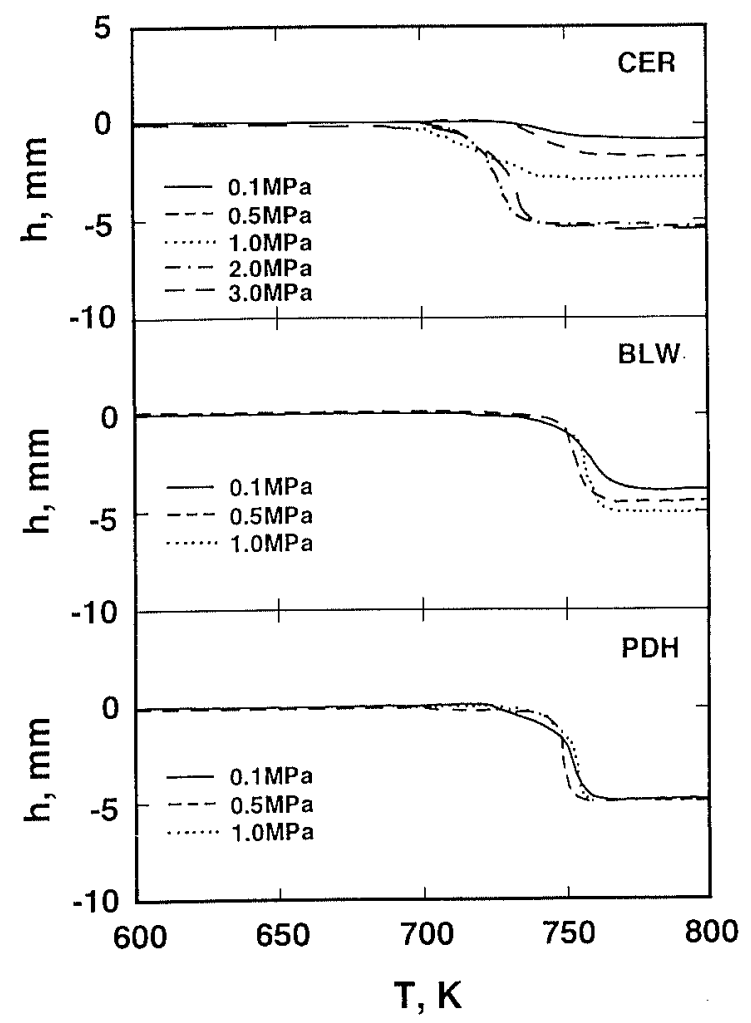

Fig. 6. Changes with temperature of net needle penetration depth at $20 \mathrm{~K} / \mathrm{min}$ up to $823 \mathrm{~K}$ for CER, BLW and $\mathrm{PDH}$ coals under 1.0 MPa.

$$
\eta=A \exp \{E /(R T)\}
$$

was employed here to describe the temperature dependency. The above equations were solved for the apparent viscosity at a temperature with a further assumption of pseudo-steady state.

Figure 7 shows a typical result of analysis for AKA coal pellet heated at $10 \mathrm{~K} / \mathrm{min}$ under $1.0 \mathrm{MPa}$. Here, logarithms of the instantaneous viscosity analyzed, $\ln \eta$, are plotted against $1 / T$ which is arisen from the Andrade equation. It is apparent from the figure that $\ln \eta$ is not a linear function of $1 / T$. In addition, the viscosity decreases from an order of $10^{8}$ to $10^{-3} \mathrm{~Pa} \cdot \mathrm{s}$ with temperature in a range of $1.5>1 / T>1.41$ and then increases up to more than $10^{5} \mathrm{~Pa} \cdot \mathrm{s}$ at higher temperatures, reflecting occurrence of softening due to pyrolysis followed by solidification due to carbonization. This ten-

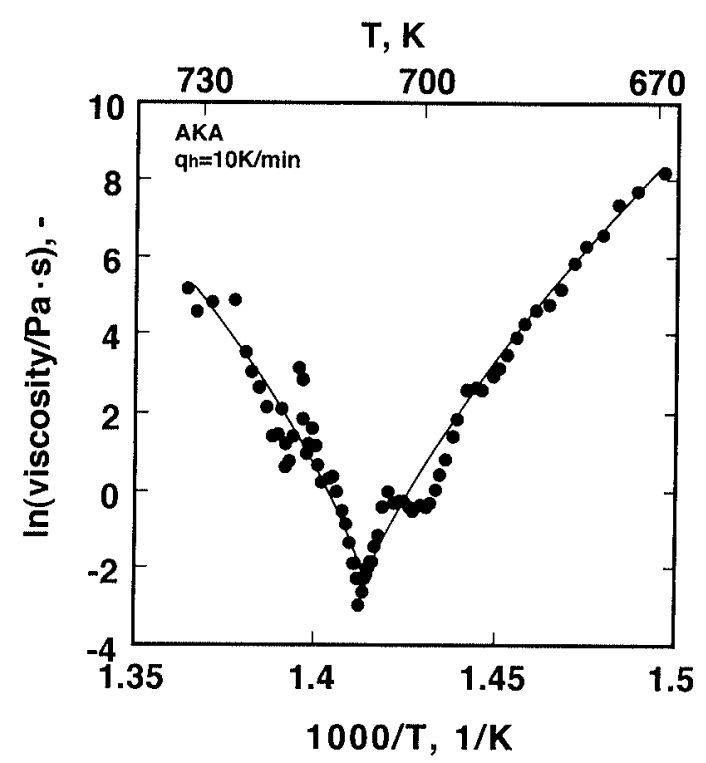

Fig. 7. Plots arisen from Andrade's equation for apparent viscosity of AKA coal.

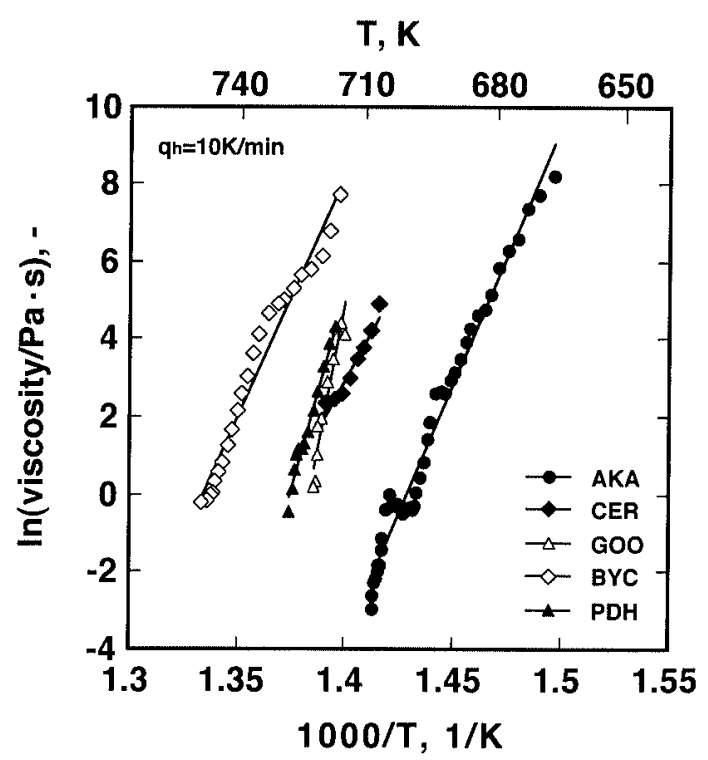

Fig. 8. Plots based on Andrade's equation for apparent viscosity of different coals within a low temperature range. 
Table 3. Dependence of apparent coal viscosity on temperature.

\begin{tabular}{cccc}
\hline Coal & $\begin{array}{c}q_{\mathrm{h}} \\
(\mathrm{K} / \mathrm{min})\end{array}$ & $\begin{array}{c}U \\
(\mathrm{~kJ} / \mathrm{mol})\end{array}$ & $\begin{array}{c}\ln (A / \mathrm{Pa} \cdot \mathrm{s}) \\
(-)\end{array}$ \\
\hline AKA & 10 & 1099 & -190 \\
CER & 10 & 874 & -145 \\
GOO & 10 & 2541 & -425 \\
BYC & 10 & 1049 & -169 \\
PDH & 10 & 1760 & -292 \\
\hline
\end{tabular}

dency was independent of operating variables such as the heating rate and the holding temperature as well as coal nature. It is hence concluded that the Andrade equation could never be applied for description of the viscosity change in the whole temperature range.

When the Andrade equation is applied for analysis of the viscosity decrease within a narrow range of temperature just after the needle penetration commenced, the viscosity is related to temperature as shown in Fig. 8 for different coals at the heating rate of $10 \mathrm{~K} / \mathrm{min}$. If the relationship between $\ln \eta$ and $1 / T$ for each coal is approximated as depicted as a straight line in the figure, the apparent activation energies for viscosity, $U$, range from 874 to $2541 \mathrm{~kJ} / \mathrm{mol}$, as listed in Table 3. These values are in the same order of magnitude as those obtained for a coal heated at different gas pressures and gas atmospheres. ${ }^{1)}$ However, as indicated by Waters, ${ }^{11}$ ) they would be unreasonably high if molecular rearrangement along with heating is responsible for the viscosity change of coal consisting of very large molecules. For temperatures higher than $600 \mathrm{~K}$, pyrolysis of coal would inevitably occur producing plastic intermediates with lower molecular weight as well as thermal fragments with higher molecular weight which is followed by semicoke formation by condensation of the molecules. From the above analysis of the needle penetration curves, it is obvious for future work that consideration of change in chemical structure of coal with temperature is essential.

\section{Conclusions}

Thermal plasticity of coal was quantitatively investigated in terms of observed needle penetration into a cylindrical pellet of pulverized coal particles and dilation of the pellet for six kinds of caking or noncaking coals. Measurements were carried out under nitrogen gas atmosphere in a range of the heating rate from 1 to $20 \mathrm{~K} / \mathrm{min}$, the holding temperature up to $823 \mathrm{~K}$ and the gas pressure from 0.1 to $3.0 \mathrm{MPa}$. The observed results showed that the needle penetration and the pellet dilation occur simultaneously and depend on the coal nature and the heating rate. In particular, coals with little softening propensity at low heating rate exhibited an appreciable softening property at high heating rate.

The apparent viscosity of the coal pellet was estimated by analyzing the net descent of the needle through the pellet on the basis of an equation of motion and Andrade's equation. However, the Andrade equation was found impossible to be applied for the observed result in the whole range of temperature. In addition, even if the application was confined to the data in a lower temperature range the estimated viscosity showed unreasonably high temperature dependency, suggesting a necessity for the analysis to consider not only physical but chemical change of coal with temperature.

\section{Acknowledgements}

The financial support of the Iron and Steel Institute of Japan (ISIJ) and of a Grant-in-Aid for Developmental Scientific Research, Ministry of Education (No. 0560720) is greatly acknowledged. The authors also wish to appreciate useful comments from Dr. S. Asada and the other members of the ISIJ Committee for New Concepts on Coal Carbonization Control for Coke Production.

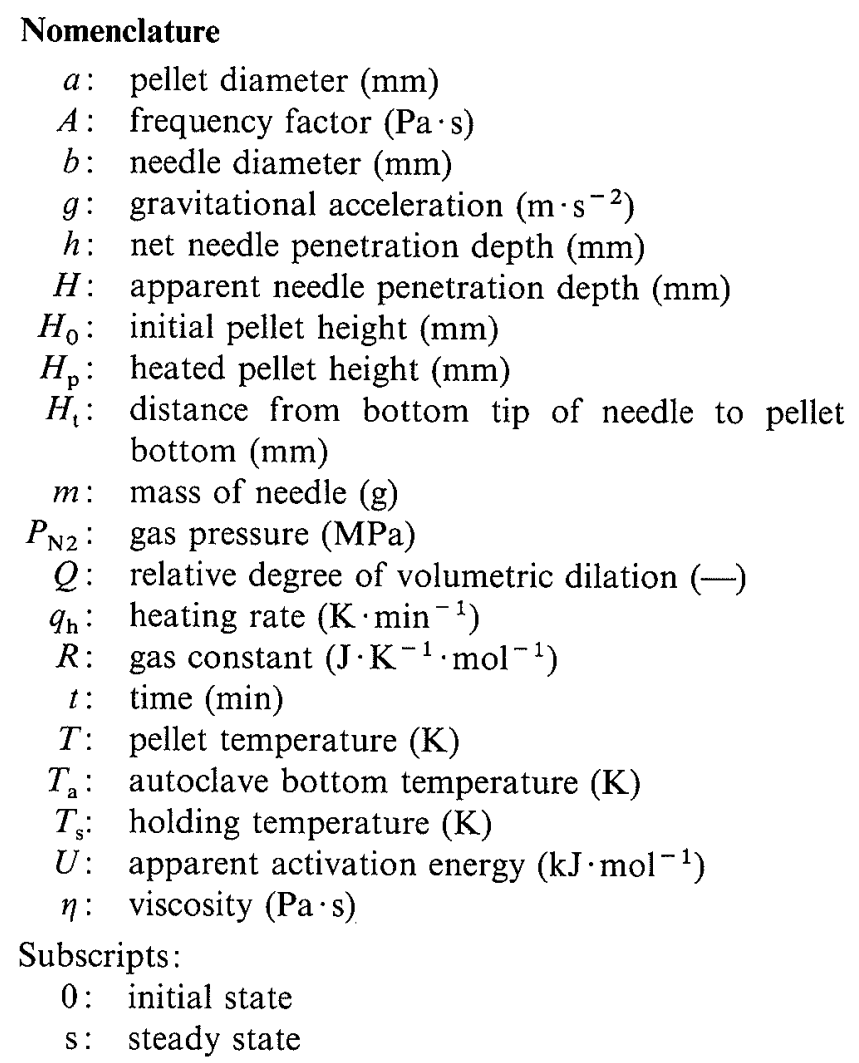

\section{REFERENCES}

1) C.-R. Deng, Y. Sanada and T. Chiba: J. Fuel Soc. Jpn., 68 (1989), 728.

2) M. Kaiho and Y. Toda: Fuel, 58 (1979), 397.

3) M. R. Khan and R. G. Jenkins: Fuel, 65 (1986), 725

4) M. R. Khan and R. G. Jenkins: Fuel, 63 (1984), 109.

5) M. R. Khan, C. W. Lee and R. G. Jenkins: Fuel Proc. Tech., 17 (1987), 63

6) T. Chiba, K. Matsuoka, S. Ikeda and Y. Sanada: Proc. of The First Int. Cong. on Sci. and Technol. of Ironmaking, ISIJ, Tokyo, (1994), 314.

7) W. S. Fong, Y. F. Khalil, W. A. Peters and J. B. Howard: Fuel, 65 (1986), 195.

8) H. Kimura and S. Fujii: Sekitankagaku-to-Kogyo, Sankyo Pub. Co., Tokyo, (1979), 265.

9) Soc. Polymer Sci. Japan: Rheology Sokuteihou, Kyoritu Pub. Co., Tokyo, (1965), 129.

10) T. Nakagawa: Rheology, 2nd ed., Iwanami Book Co., Tokyo, (1983), 206.

11) P. L. Waters: Fuel, 41 (1962), 3. 